\title{
Local Heat-Transfer Measurements on a Large, Scale-Model Turbine Blade Airfoil Using a Composite of a Heater Element and Liquid Crystals
}

S.A. Hippensteele, L.M. Russell, and F.J. Torres

Lewis Research Center Cleveland, Ohio

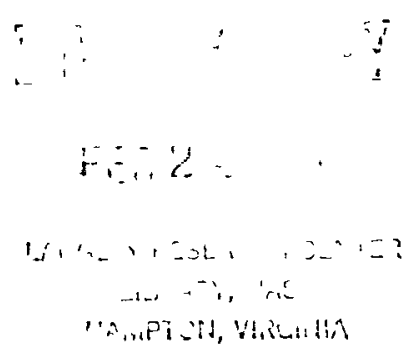

Prepared for the

Thirtieth International Gas Turbine Conference and Exhibit sponsored by the American Society of Mechanical Engineers Houston, Texas, March 17-21, 1985 
LOCAL HEAT-TRANSFER MEASUREMENTS ON A LARGE, SCALE-MODEL TURBINE BLADE

\author{
AIRFOIL USING A COMPOSITE OF A HEATER ELEMENT AND LIQUID CRYSTALS
}

\author{
S.A. Hippensteele, L.M. Russe11, and F.J. Torres \\ National Aeronautics and Space Administration \\ Lewis Research Center \\ Cleveland, Ohio 44135
}

\begin{abstract}
SUMMARY
Local heat-transfer coefficients were experimentally mapped along the midchord of a five-times-size turbine biade airfoil in a static cascade operated at room temperature over a range of Reynolds numbers. The test surface consisted of a composite of commercialiy available materials: a mylar sheet with a layer of cholesteric liquid crystals, which change color with temperature, and a heater sheet made of a carbon-impregnated paper, which produces uniform heat flux. After the initial selection and calibration of the composite sheet, accurate, quantitative, and continuous heat-transfer coefficients were mapped over the airfoil surface. The local heat-transfer coefficients are presented for Reynolds numbers from $2.8 \times 10^{5}$ to $7.6 \times 10^{5}$. Comparisons are made with analytical values of heat-transfer coefficients obtained from the STAN5 boundary-layer code. Also, a leading-edge separation bubble was revealed by thermal and flow visualization.
\end{abstract}

\title{
INTRODUCTION
}

As gas turbine inlet temperatures and pressures increase, the heat loads to the turbine also increase. Consequently, more complex turbine blade cooling configurations are needed to provide acceptable metal temperatures and component life. The attainment of accurate metal temperature predictions and effectively cooled and durable parts requires accurate knowledge of high-resolution heat-transfer coefficients. A common method used to determine these coefficients consists of finite heater strips with thermocouples (refs. 1 and 2). This method, however, only provides average heat-transfer coefficients over intermittant selected areas and is generally used in one-dimensional idealizations of the problem. As a consequence, methods for measuring highresolution heat-transfer are needed, particularly at near-room-temperature conditions, where the investigation can be conducted at relatively low cost and both turbine flow and heat-transfer dimensionless parameters can be preserved.

This study demonstrates the method of using a liquid crystal/heater composite sheet for heat-transfer research and to verify accuracy and resolution of the resulting heat-transfer coefficients. Reference 3 reported on the potential of using this method for obtaining heat-transfer measurements. The present report gives actual, quantitative, and continuous heat-transfer coefficients on a model turbine blade.

Liquid crystals, by virtue of their property of changing color with temperature, provide a measurement of the continuous temperature and a visualization of thermal patterns. Applying liquid crystals to a uniform heater element and using a heat balance along with the measured electrical input power provide a measure of the local heat-transfer coefficient and its distribution. 
More information about the nature of liquid crystals and more detail about the uniform heater element are available (ref. 3 ). Liquid crystals have often been used to indicate temperatures (ref. 4). In heat-transfer research, liquid crystals have been sprayed on test surfaces or on carbon-impregnated paper attached to a test surface (refs. 5 to 8 ). The unique features of the composite sheet used for this report are its simplicity and uniformity and its use of commercially available materials. This composite was wrapped around the airfoil of the test blade. The test blade was in the center position of a fiveblade cascade test section. The test section was part of an atmospheric flow tunne 1 which was connected to a vacuum exhaust system. The tests were run at room temperature and pressure. The gas-stream Reynolds number varied from $2.8 \times 10^{5}$ to $7.6 \times 10^{5}$ (based on actual chord).

This paper presents quantitative, experimental heat-transfer coefficients around a five-times-size model of a typical high-temperature gas turbine blade airfoil using a liquid crystal/heater composite sheet. In order to lend credence to this method, the results are compared with predicted results obtained using a computer code. Since, in this study, the blade surface was heated and the free stream was at room temperature, the direction of heat-transfer is the opposite of what it would be in a real engine with its hot free stream. Areas of high heat-transfer in this study resulted in lower surface temperatures. Turbulence measurements and flow visualization results are also presented.

\section{NOMENCLATURE}
A heated area
a constant
C, d constants
E voltage across heater sheet
h heat-transfer coefficient
I current through heater sheet
$k$ thermal conductivity
$L$ vertical distance
$P$ total pressure
p static pressure
$Q$ heat flux
Re inlet Reynolds number based on actual blade chord
$S$ actual chord length
$T$ temperature
$\Delta \quad$ difference
$\delta$ uncertainty

Subscripts:

a air 


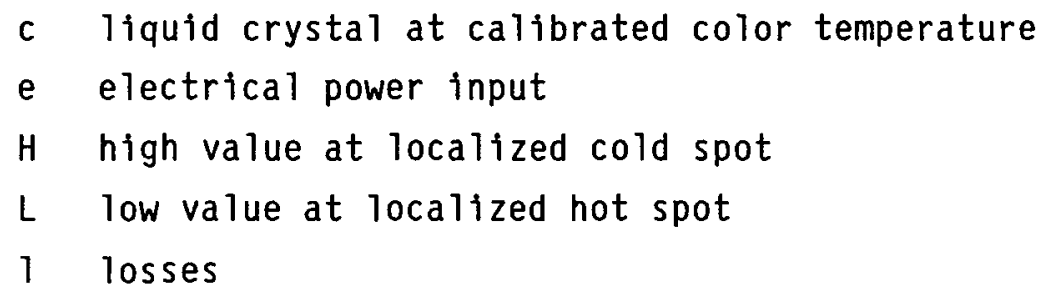

APPARATUS

Figure 1 is a photograph of the test section showing the five-blade, twodimensional cascade which simulates a turbine blade row. The blade profile was five times the size of an existing high-temperature turbine blade. The liquid crystal/heater composite was wrapped completely around the wooden blade and attached to the airfoil surface of the center blade. The free-stream velocity upstream of the blades was measured with the static and total head probes.

Figure 2 is a schematic of the test facility. Room-temperature air was drawn through the tunnel which, except for the inlet and flow straightener sections, was made of clear acrylic plastic and was $15.2 \mathrm{~cm}(6.0 \mathrm{in})$ high. The width was set to $36.8 \mathrm{~cm}(14.5 \mathrm{in})$ by a pair of headboards which extended from the metal inlet section to the blade row leading edge. Tailboards were also used to assure periodicity at the blade row exit. The tunnel is capable of handling up to $4.5 \mathrm{~kg} / \mathrm{sec}(10 \mathrm{lb} / \mathrm{sec})$ of air with the existing test section installed. The maximum velocity attainable was about $70 \mathrm{~m} / \mathrm{sec}(230 \mathrm{ft} / \mathrm{sec})$. This velocity produced an inlet Reynolds number (based on actual chord) of $7.6 \times 10^{5}$ which simulates the inlet Reynolds number of typical high-temperature turbines. Typical Mach numbers could not be simulated because of the velocity limitation.

A cross section of the complete liquid crystal/heater composite is shown in figure 3. The liquid-crystal sheet was bonded to the heater sheet with a double-coated adhesive material. The same type of adhesive was used to bond the composite sheet to the test blade surface. The total thickness of the composite was $1.17 \mathrm{~mm}(0.046 \mathrm{in})$. The liquid-crystal sheet, purchased commercially, consisted of cholesteric-type liquid crystals, which change color with temperature, laid on transparent Mylar covered by a black plastic sealing material. The overall thickness of the liquid-crystal sheet was $0.20 \mathrm{~mm}$ $(0.008 \mathrm{in})$. The heater element, also commercially purchased, was a carbonimpregnated cardboard-like material with a thickness of $0.76 \mathrm{~mm}(0.030 \mathrm{in})$ and a resistivity of $55 \Omega / s q$ (resistance of any square-shaped area). Copper foil bus bars were attached to the heater sheet at the hub and tip ends of the blade, and a conductive silver paint was used to ensure good electrical contact. Electrical energy was supplied to copper foil bus bars. The power source was a controllable electric power supply capable of supplying up to $80 \mathrm{~V}$ at $25 \mathrm{~A}$.

\section{PROCEDURE}

\section{Experimental Heat-Transfer Coefficients}

The blade-surface heat-transfer coefficient can be derived from an energy balance on the blade airfoil model: 


$$
Q_{e}-Q_{1}=h A\left(T_{c}-T_{a}\right)
$$

Knowing the measured heat input $Q_{e}$ to the sheet (less heat losses) with heated area $A$ and the free-stream air temperature $T_{a}$, the local heattransfer coefficient $h$ can be calculated at the location of the yellow-color band (an isotherm having a uniform heat-transfer coefficient produced by a uniform heat $f(u x)$. The total heat energy $Q_{e}$ supplied to the heater sheet was calculated from the measured voltage $E$ across the heater sheet and the current I through a shunt resistor in series with the heater sheet. The heater current was calculated from the measured voltage across the shunt resistor having a known resistance. The heat energy lost $Q_{1}$ is due to conduction through the blade and radiation from the blade. The area $A$ is the measured heated area of the heater sheet. The temperature of the yellow-color band $T_{c}$ in the liquid-crystal sheet was determined from a water calibration. The temperature of the upstream, inlet free-stream air $\mathrm{T}_{\mathrm{a}}$ was measured by the same precision resistance digital thermometer used to calibrate the liquid-crystal yellow-color temperature. Because the technique is new and there is little quantitative experience with it, an error analysis is detailed in the appendix.

\section{Calibration}

The liquid-crystal sheet was calibrated for yellow-color-temperature correspondence and uniformity by immersing the sheet in a hot water bath and observing and photographing the color changes as the water gradually cooled to room temperature. The water bath was stirred before the temperature measurement and photographs were taken. The water temperature was measured by a precision resistance digital thermometer. The blue color corresponded to the highest temperatures with green, yellow, reddish-brown, and black corresponding to decreasing levels of temperature. As discussed in reference 3 , the yellow color occurred over the narrowest temperature band. Therefore, the yellow color was used as the calibration temperature.

The accuracy of the heat-transfer coefficient depends on the uniformity of the heater-element sheet. To measure the uniformity of the heat flux produced by the heater sheet, a temporary composite was made. This temporary composite consisted of a liquid-crystal sheet having a very uniform yellow-colortemperature response and a heater sheet, which was larger than but contained the area to be used on the test blade. Electrical power was supplied to this large temporary composite through copper bus bars while it was suspended horizontally in a dead air space. Electrical voltage measurements were made (ref. 3) and were used to calculate the local-heat-flux percentage deviation from the overall heater-sheet average heat flux. The area with the most uniform yellow-color distribution (hence, uniform temperature and heat flux) in the large, temporary heater sheet was then used on the test blade.

Previous experience with liquid crystals indicates that viewing angle and incident light angle have some effect on the resultant color (ref. 3). Photographs taken showed what effects the camera-viewing and strobe-aiming angles had on the liquid-crystal sheet heated to produce a yellow color. It was found that if the angle between the camera-view and the strobe-aiming was less than $30^{\circ}$, then there was no significant color change in the yellow color, regardless of the angle of the liquid-crystal sheet. For angles between the camera-view and the strobe-aiming greater than $30^{\circ}$, the color shifted from yellow toward blue, erroneously indicating a temperature greater than that of the calibrated 
yellow color. For this reason, the tests for this study were conducted at included angles less than $30^{\circ}$.

\section{Testing}

Before the turbine blade tests were performed, the free-stream turbulence intensity level of the tunnel was established. The measurement was made with a hot-wire anemometer at three free-stream tunnel velocities: 24,37 , and $70 \mathrm{~m} / \mathrm{sec}(78,120$, and $230 \mathrm{ft} / \mathrm{sec})$. The average turbulence intensity was 0.7 percent. This value is lower than in a typical engine, but it is typical of wind tunnels. Generally, tests were made at the three free-stream inlet velocities: 24,37 , and $70 \mathrm{~m} / \mathrm{sec}(78,120$, and $230 \mathrm{ft} / \mathrm{sec})$. The procedure was to first bring the tunnel to the desired velocity as measured by the total and static pressure probes to produce the proper Reynolds number. Electric power was then supplied to the composite sheet raising its temperature to the point at which the colors began to appear. The power input was "fine tuned" to obtain the desired calibrated yellow color in the locations of interest. The location of the yellow-color band was varied over the airfoil surface by changing the heat input while free-stream velocity remained the same.

Sufficient time had to be given to allow temperatures and the yellow-color band to stabilize. Typically, the first data point in a series of test runs was not taken until about 1 hour had elapsed at one combination of Reynolds number and electrical power input. Thereafter, data points were taken about every 20 to 30 minutes. Data were in the form of color transparencies (slides give consistant color balance results) taken with a $35 \mathrm{~mm}$ camera to record the yellow-color locations and the simultaneous documentation of air velocity, power input, air temperature, and pressure. The yellow-color location was established by photographing a grid containing the blade surface coordinates placed on the blade before the test run. The data pictures showing the yellowcolor band and the grid photograph showing the blade surface coordinates were coordinated by using two white reference dots located on the blade and in plain view for each picture (see fig. 4). The coordination process was accomplished by projecting the pictures onto a digitizing table, manually digitizing the locations of the reference dots, grid coordinates, and yellow-color bands, and calculating the yellow-color band locations using a computer.

\section{Analytical Heat-Transfer Coefficients}

It is useful to compare the results of any new experimental technique with similar experimental data and analytical results. The primary tools for an analytical simulation were the STAN5 boundary-layer code (refs. 10 and 11) and the measured inlet flow conditions. The velocity profiles were derived from the measured pressures. There were several models and assumptions available as to the location and type of transition from laminar to turbulent boundary-layer flow. The most useful procedure was to choose an instantaneous transition at a momentum thickness Reynolds number of 200 for the first trial. This usually yielded a visible discontinuity in the plotted distributions, marking the general locations of the transition zone. This made possible a second trial, selecting a gradual, smooth transition starting slightly upstream of the discontinuity. It was possible, by comparing the heat-transfer-coefficient distributions obtained by using the maximum and minimum heat fluxes, to determine how much the heat-transfer coefficient varied with the heat flux and whether additional computer simulations were necessary for the intermediate heat fluxes. 


\section{RESULTS AND DISCUSSION}

\section{Pressure Distribution}

Measurements were made of the pressure distribution around the midspan of the airfoil surface at the three free-stream velocities. Pressures were measured at 30 locations using a scannivalve system. A plot of the results at maximum velocity is shown in figure 5. A large unfavorable pressure gradient on the pressure side near the leading edge is shown in the figure. The calculated critical velocity ratio distribution for this blade profile also indicated a possible flow separation problem just downstream of the leading-edge pressure surface.

\section{Flow Separation}

Figure $6(a)$ is a view looking obliquely down at the pressure side of the test blade during a run. At this lowest Reynolds number (based on actual chord) of $2.8 \times 10^{5}$ and the lowest heat flux input of $1788 \mathrm{~W} / \mathrm{m}^{2}$ (567 Btu/(hr) $\left.\left(\mathrm{ft}^{2}\right)\right)$, evidence of a flow separation bubble at a pressure surface distance of about $1.91 \mathrm{~cm}(0.75 \mathrm{in})$ from the leading edge is clearly visible. Since the free-stream air is at room temperature and the test surface is heated, the dark blue (hot) region just behind the leading edge is an area of low heat transfer, indicating that the flow has stagnated in this region. This is where the bubble is presumed to have formed. The black (cool) area just downstream of this region is an area of high heat-transfer between the free stream and the surface, probably because of the air reattaching to the surface after it had passed over the bubble. (Of course, in a real engine with its hot free stream, this bubble region would be a relatively cool spot. This would cause surface temperature gradients with their associated potential for damage due to high stresses.) The hot region produced by this separation bubble is still present (see fig. 6(b)) at the highest Reynolds number of $7.6 \times 10^{5}$ and the highest heat flux input of $5252 \mathrm{~W} / \mathrm{m}^{2}\left(1666 \mathrm{Btu} /(\mathrm{hr})\left(\mathrm{ft}^{2}\right)\right)$. Down-stream of the hot area, the color pattern appears normal with fairly even temperature until the trailingedge region. The cool (black) strip along the top edge of the surface is the tip end copper bus bar location. In some cases, for example, near the leadingedge separation bubble region, the yellow band is very narrow. This represents a large chordwise temperature gradient. Where the yellow band occurs over a wider area, a relatively small temperature gradient exists.

To visualize the flow over the separation bubble, yellow-pigmented oil was used. Figure $7(a)$ shows yellow 011 applied over the blade pressure surface before initiation of airflow. Figure $7(\mathrm{~b})$ shows the yellow-0il trace after about 2 minutes of airflow at up to $18 \mathrm{~m} / \mathrm{sec}(58 \mathrm{ft} / \mathrm{sec})$. The separation bubble is shown where the yellow oil accumulates instead of flowing downstream. A weak separation bubble was also discovered at a surface distance of $12.7 \mathrm{~cm}$ ( 5.0 in) on the suction side (see fig. $7(\mathrm{c})$ ).

\section{Experimental Heat Transfer}

Figure 8 shows views of the suction side of the blade. Because of surface curvature, three views had to be used to map the local heat-transfer coefficlent over the entire suction surface. The electrical power was varied in the three views as needed to show the yellow-color bands over the entire surface 
at each Reynolds number. Figure $8(a)$ shows the leading-edge region of the blade. An area of high heat transfer is indicated around the leading edge, then a fairly large chordwise temperature gradient (high heat-transfercoefficient gradient) through the yellow area, followed by an even value further downstream. Figures $8(b)$ and $(c)$ show the midchord and trailing-edge regions. Figure $8(b)$ shows a spanwise periodic temperature pattern existing upstream in a small temperature gradient region. Comparative measurements indicate that this pattern is probably caused by the straws in the flow straightener section at the inlet. Further study in this area is recommended. It should be pointed out that this pattern might have gone unnoticed if thermocouples had been used instead of liquid crystals with their high-resolution capability. The converging yellow lines in the streamwise direction show increasing cool areas downstream (see fig. $8(\mathrm{c})$ ) where the endwall passage vortex (ref. 9) sweeps across the surface.

The very narrow yellow band (fig. $8(\mathrm{c})$ ) indicates a very large chordwise temperature gradient (heat-transfer-coefficient gradient) existed. The location of the large gradient was near the minimum passage area (throat area) where the neighboring blade trailing edge was located and the airflow was no longer guided.

Figure 9 shows the suction-side trailing edge where another spanwise periodic temperature pattern existed in a small temperature gradient region. This pattern is similar to the one seen upstream ( $\mathrm{fig} .8(\mathrm{~b})$ ) and is also probably caused by the straw straighteners.

\section{Experimental Heat-Transfer Coefficients}

The major objective of the program described here was to obtain a plot of quantitative heat-transfer coefficients with blade surface distance (see fig. 10). By calibration, the color-temperature correspondence was established for the particular liquid-crystal sheet used. The yellow color for this experiment corresponded to a temperature $T_{C}$ of $40.9^{\circ} \mathrm{C}\left(105.6{ }^{\circ} \mathrm{F}\right)$. The heaterelement sheet uniformity produced a heat-flux to within 6.0 percent of the overall heater-sheet average heat-flux value. The calibration and measurement accuracies are presented in the appendix. Heat-transfer coefficients $h_{e}$ (ignoring the small heat losses) were calculated as a function of surface distance for three free-stream Reynolds numbers (based on actual chord) $7.6 \times 10^{5}, 4.2 \times 10^{5}$, and $2.8 \times 10^{5}$.

The heat-transfer coefficient at the leading edge was very high, but it dropped to a minimum in the pressure surface separation bubble region. After the separation bubble, the coefficient reached a peak as the flow reattached. On the suction surface the heat-transfer coefficient was very high at the leading edge, decreased with surface distance to a minimum at the throat region, and then increased rapidly near the trailing edge where the flow was no longer guided by the neighboring blade.

\section{Analytical Heat-Transfer Coefficients}

The analytical results show that on both the pressure and suction sides there was a pronounced dip in the heat-transfer coefficient at a single point per side (see figs. 11 and 12). On the pressure side, this drop, which also 
showed up on the friction factor plot (see fig. 11(b)), coincided with the location of the separation bubble region previously mentioned. This suggested there might be a similar separation on the suction side (see fig. 12). Indeed, this proved to be the case, as a region of weak separation was later found experimentally by flow visualization using yellow pigmented oil at the same location that the simulation predicted (see fig. $7(\mathrm{c})$ ). The oscillating, analytical points were caused by instability calculations in the STAN5 boundary-layer code.

The predicted and measured heat-transfer-coefficient plots followed similar curve shapes and had similar values for both the suction and pressure sides, although the calculated curves were displaced slightly in the surface-distance direction. The maximum and minimum heat-flux cases did not differ significantly to require intermediate heat flux computer simulations. Thus, the experimental technique discussed herein provides good quantitative results, and this was given credence by the computer simulation.

\section{CONCLUDING REMARKS}

The results indicate that this composite of a liquid-crystal sheet and a heater-element sheet bonded to a model turbine blade provides an accurate, quantitative, and continuous map of heat-transfer coefficients on the blade surface. The effect of a suspected separation bubble on the pressure surface of the blade was clearly revealed in the photographs showing the colortemperature patterns. The maximum error in the experimental heat-transfer coefficients was 6.2 percent with a maximum heat loss due to blade-chord-plane conduction of $4.94 \mathrm{~W} /\left(\mathrm{m}^{2}\right)\left({ }^{\circ} \mathrm{C}\right)\left(0.87 \mathrm{Btu} /(\mathrm{hr})\left(\mathrm{ft}^{2}\right)\left({ }^{\circ} \mathrm{F}\right)\right)$, as presented in the appendix.

The temperature patterns observed and the heat-transfer coefficients found were consistent with pressure distribution measurements and analytical heat-transfer calculations. 


\section{APPENDIX - ERROR ANALYSIS \\ ERRORS IN MEASUREMENTS}

The maximum errors in the experimental measurements are as follows:

Digital voltmeters................... . . . . . . . . . . . .

Shunt resistor (for measuring current) .............. $\pm 1.0 \%$

Uniformity in heater sheet heat flux............... $\pm 6.0 \%$

Area of heater sheet . . . . . . . . . . . . . . . . . $\pm 7.0 \%$

Yellow-color temperature of liquid-crystal sheet...... $\pm .06^{\circ} \mathrm{C}\left(0 . \overline{1}^{\circ} \mathrm{F}\right)$

Air temperature ............... ... $11{ }^{\circ} \mathrm{C}\left(0.2^{\circ}{ }^{\circ} \mathrm{F}\right)$ (or $\left.\pm 0.04 \%\right)$

Differential pressure transducer . . . . . . . . . . . . . $\pm 3.7 \%$

Absolute pressure gauge . . . . . . . . . . . . . . $\pm 0.5 \%$

Blade chord (actua1) . . . . . . . . . . . . . . $\pm 0.6 \%$

As described in reference 3 , the maximum error in the heat-flux uniformity within a heater sheet is given by

$$
\left(E_{H}^{2}-E_{L}^{2}\right) /\left(E_{H}^{2}+E_{L}^{2}\right)
$$

This assumes that the average heat flux of the heater sheet equals the median value of the extreme local hot- and cold-spot heat-flux values.

\section{ERROR IN HEAT-TRANSFER COEFFICIENT}

The maximum errors in the terms that were used to calculate $h_{e}$ from

equation (1) are as follows:
Heater-sheet heat-flux uniformity, $\left(E_{H}^{2}-E_{L}^{2}\right) /\left(E_{H}^{2}+E_{L}^{2}\right) \cdots \cdots+\ldots \ldots$

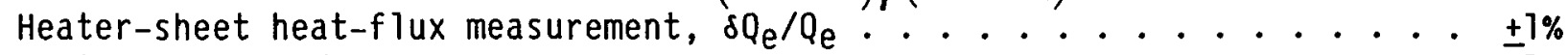

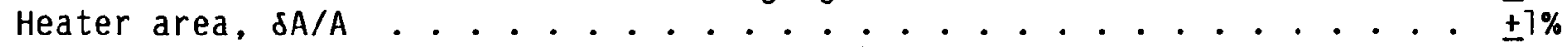
Temperature difference, $\delta\left(T_{c}-T_{a}\right) /\left(T_{c}-T_{a}\right) . . . . . . . . . \pm \pm \%$

A maximum temperature difference of $0.05{ }^{\circ} \mathrm{C}\left(0.09^{\circ} \mathrm{F}\right)$ across the $0.1143-\mathrm{mm}-$ $(0.0045-$ in-) thick Mylar sheet (between the liquid-crystal layer and the air stream) was also included along with fluctuation and reading errors in air temperature of $0.12{ }^{\circ} \mathrm{C}\left(0.21^{\circ} \mathrm{F}\right)$. Therefore, as defined in reference 12 , the error in $h_{e}$ was

$$
\begin{aligned}
\frac{\delta h_{e}}{h_{e}}=\sqrt{\left(\frac{E_{H}^{2}-E_{L}^{2}}{E_{H}^{2}+E_{L}^{2}}\right)^{2}+\left(\frac{\delta Q_{e}}{Q_{e}}\right)^{2}+\left(\frac{\delta A}{A}\right)^{2}+\left(\frac{\delta\left(T_{c}-T_{a}\right)}{T_{c}-T_{a}}\right)^{2}} \\
=\sqrt{(0.06)^{2}+(0.01)^{2}+(0.01)^{2}+(0.01)^{2}}= \pm 6.2 \%
\end{aligned}
$$


An additional error in the heat-transfer coefficient existed due to heat losses caused by radiation and conduction.

The maximum loss due to radiation was calculated by assuming an emissivity and configuration factor value of 1 , and it was found to be negligible. The spanwise component of the conduction heat loss was eliminated by selecting the yellow-color-band locations near the blade midspan where no spanwise heat transfer existed. The only remaining heat loss (conduction through the bladechord plane) was determined by making a measurement of the total heat input for a no-airflow condition and then subtracting a calculated free-convection heat 1oss.

In reference 13, the calculated free-convection heat-transfer coefficient on a vertical surface with no airflow is given as

$$
h=C \frac{k}{L}\left(a L^{3} \Delta T\right)^{d}
$$

where

$C=0.55$

$a=7.374 \times 10^{7} /\left(\mathrm{m}^{3}\right)\left({ }^{\circ} \mathrm{C}\right)\left(1.160 \times 10^{6} /\left(\mathrm{ft} \mathrm{t}^{3}\right)\left({ }^{\circ} \mathrm{F}\right)\right)$

$d=1 / 4$

$T_{C}=40.89^{\circ} \mathrm{C}\left(105.6{ }^{\circ} \mathrm{F}\right)$

$\mathrm{T}_{\mathrm{a}}=15.17^{\circ} \mathrm{C}\left(59.3^{\circ} \mathrm{F}\right)$

$\Delta T=25.72^{\circ} \mathrm{C}\left(46.3^{\circ} \mathrm{F}\right)$

$k=0.0277 \mathrm{~W} /(\mathrm{m})\left({ }^{\circ} \mathrm{C}\right)\left(0.016 \mathrm{Btu} /(\mathrm{hr})(\mathrm{ft})\left({ }^{\circ} \mathrm{F}\right)\right)$

$L=0.1016 \mathrm{~m}(0.3333 \mathrm{ft})$

from which

$h=5.62 \mathrm{~W} /\left(\mathrm{m}^{2}\right)\left({ }^{\circ} \mathrm{C}\right)\left(0.99 \mathrm{Btu} /(\mathrm{hr})\left(\mathrm{ft} \mathrm{t}^{2}\right)\left({ }^{\circ} \mathrm{F}\right)\right)$

The average heat-transfer coefficient determined from measurements made for the no-airflow condition was $10.55 \mathrm{~W} /\left(\mathrm{m}^{2}\right)\left({ }^{\circ} \mathrm{C}\right)\left(1.86 \mathrm{Btu} /(\mathrm{hr})\left(\mathrm{ft}^{2}\right)\left({ }^{\circ} \mathrm{F}\right)\right)$.

Therefore, the heat-transfer loss expressed in terms of a heat-transfer coefficient $h_{1}$ due to conduction through the blade-chord plane was the difference (for the no-airflow condition) between the total measured value and the freeconvection value or $4.94 \mathrm{~W} /\left(\mathrm{m}^{2}\right)\left({ }^{\circ} \mathrm{C}\right)\left(0.87 \mathrm{Btu} /(\mathrm{hr})\left(\mathrm{ft}^{2}\right)\left({ }^{\circ} \mathrm{F}\right)\right)$. And finally, the maximum error in the experimental heat-transfer coefficient $h_{e}$ was $+6.2 \%$ with a maximum heat loss due to blade-chord-plane conduction of $4.94 \mathrm{~W} /\left(\mathrm{m}^{2}\right)\left({ }^{\circ} \mathrm{C}\right)$ $\left(0.87 \mathrm{Btu} /(\mathrm{hr})\left(\mathrm{ft}^{2}\right)\left({ }^{\circ} \mathrm{F}\right)\right)$.

The error in the location of the $h_{e}$ data points (yellow-color bands) was $\pm 1.27 \mathrm{~mm}(0.05 \mathrm{in})$. 


\section{ERROR IN REYNOLDS NUMBER}

The maximum errors in the experimental measurements of Re are as follows:

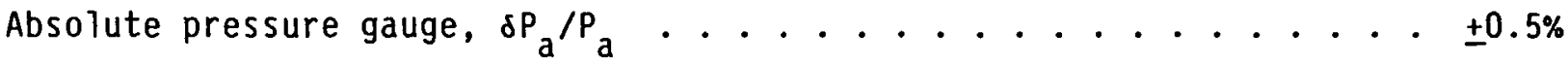
Differential pressure transducer:

For velocity, $\delta \Delta \mathrm{P}_{\mathrm{a}} / \Delta \mathrm{P}_{\mathrm{a}}$. . . . . . . . . . . . . . . . $\pm 8.4 \%$

For flow straightener section, $\delta \Delta \mathrm{P}_{\mathrm{a}} / \Delta \mathrm{P}_{\mathrm{a}}$. . . . . . . . . . . $\pm 7.9 \%$ Blade actual chord, $\delta S / S . . . . . . . . . . . . . . . \pm \pm 0.6 \%$ Air temperature, $\delta \mathrm{T}_{\mathrm{a}} / \mathrm{T}_{\mathrm{a}}$. . . . . . . . . . . . . . . . $\pm 0.04 \%$

Therefore, as defined in reference 12, the error in $\operatorname{Re}$ was

$$
\begin{aligned}
\frac{\delta R e}{\operatorname{Re}} & =\sqrt{\left[\frac{1}{2} \sqrt{\left(\frac{\delta P_{a}}{P_{a}}\right)^{2}+\left(\frac{\delta \Delta P_{a}}{\Delta P_{a}}\right)^{2}}\right]^{2}+\left(\frac{\delta T_{a}}{T_{a}}\right)^{2}+\left[\frac{1}{2}\left(\frac{\delta \Delta P_{a}}{\Delta P_{a}}\right)\right]^{2}+\left(\frac{\delta S}{S}\right)^{2}} \\
& =\sqrt{\left[\frac{1}{2} \sqrt{(0.005)^{2}+(0.079)^{2}}\right]^{2}+(0.0004)^{2}+\left[\frac{1}{2}(0.084)\right]^{2}+(0.006)^{2}} \\
& = \pm 5.8 \%
\end{aligned}
$$




\section{REFERENCES}

1. Florschuetz, L.W., et al., "Multiple Jet Impingement Heat Transfer Charac-teristic: Experimental Investigation of In-Line and Staggered Arrays with Crossflow," NASA CR-3217, 1980.

2. Van Fossen, G.J., et al., "Heat Transfer Distributions Around Nominal Ice Accretion Shapes Formed on a Cylinder in the NASA Lewis Icing Research Tunnel," AIAA Paper 84-0017, Jan. 1984.

3. Hippensteele, S.A., Russe11, L.M., and Stepka, F.S., "Evaluation of a Method for Heat Transfer Measurements and Thermal Visualization Using a Composite of a Heater Element and Liquid Crystals," Journal of Heat Transfer, Vol. 105, No. 1, Feb. 1983, pp. 184-189.

4. Fergason, J.L., "Liquid Crysta1s," Scientific American, Vo1. 211, No. 2, Aug. 1964, pp. 76-85.

5. den Ouden, C., and Hoogendoorn, C.J., "Local Convective-Heat Transfer Coefficients for Jets Impinging on a Plate. Experiments Using a LiquidCrystal Technique," Heat Transfer, Proceedings of the Fifth International Heat Transfer Conference, Vol. V, Japan Society of Mechanical Engineering, Tokyo, Japan, 1974, pp. 293-297.

6. Cooper, T.E., Field, R.J., and Meyer, J.F., "Liquid Crystal Thermography and Its Application to the Study of Convective Heat Transfer, Journal of Heat Transfer, Vol. 97, No. 3, Aug. 1975, pp. 442-450.

7. Durao, M.D.C., "Investigation of Heat Transfer in Straight and Curved Rectangular Ducts Using Liquid Crystal Thermography," M.S. Thesis, Naval Post-graduate School, Monterey, CA., June 1977 (AD-A045131).

8. Moody, H.L., and Jeche1, K., "Heat Transfer Measurements in Cold Wind Tunne 1s," AFWAL-TR-81-3176, Wright-Patterson Air Force Base, Ohio, Sept. 1982 .

9. Gaugler, R.E., and Russe11, L.M., "Streakline Flow Visualization Study of a Horseshoe Vortex in a Large-Scale. Two-Dimensional Turbine Stator Cascade," ASME Paper 80-GT-4, Mar. 1980.

10. Crawford, M.E., and Kays, W.M., "STAN5: A Program for Numerical Computation of Two-Dimensional Internal and External Boundary Layer Flows, "NASA CR-2742, 1976.

11. Gaugler, R.E., "Some Modifications to, and Operational Experiences with, the Two-Dimensional, Finite-Difference, Boundary Layer Code, STAN5," presented at the Gas Turbine Conference and Products Show, ASME Paper 81-GT-89, Mar. 1987 .

12. Taylor, J.R., "An Introduction to Error Analysis," University Science Books, Mill Va Tley, CA, 1982.

13. Brown, A.I., and Marco, S.M., Introduction to Heat Transfer, 3rd ed., McGraw-Hi11, New York, 1958. 


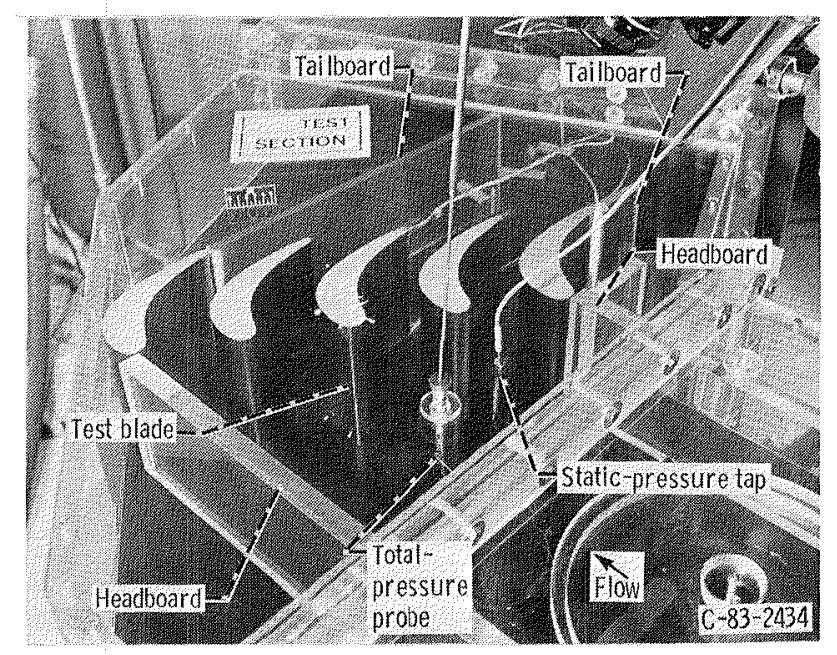

Figure 1. - Closeup view of test section.

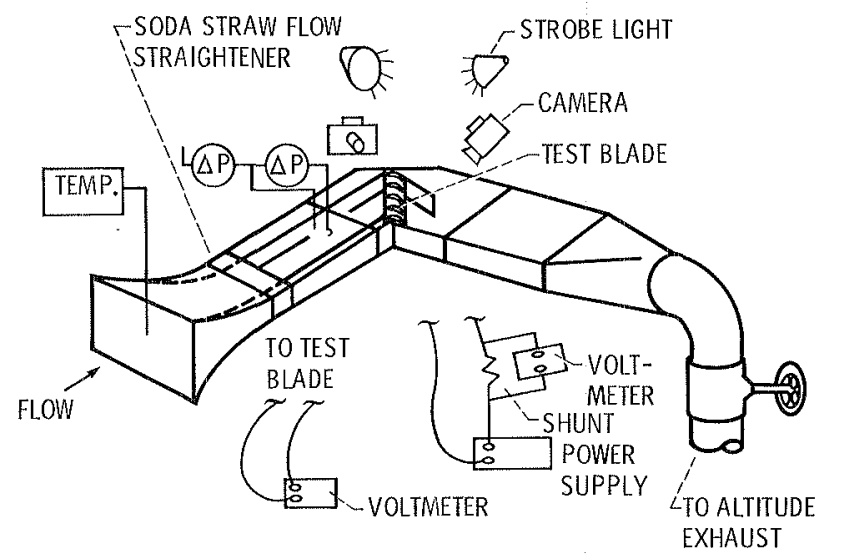

Figure 2. - Schematic of test facility.

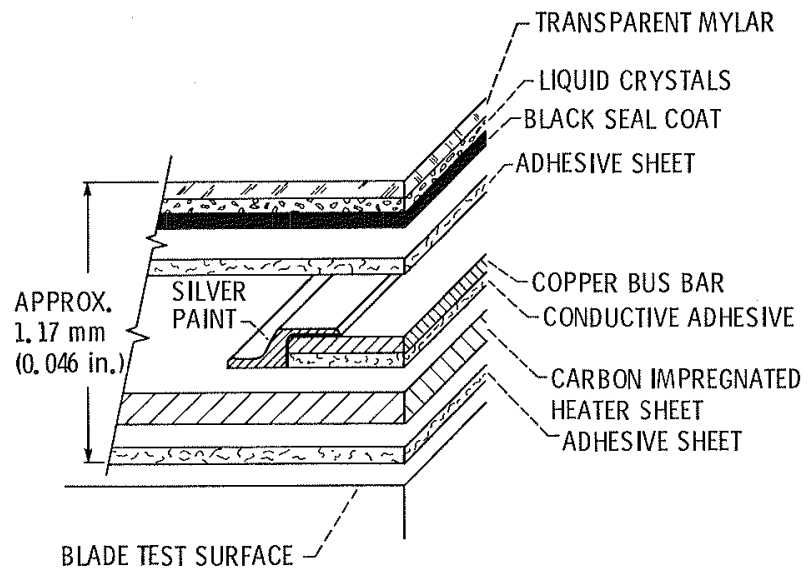

Figure 3. - Cross-section of the liquid crystal/heater composite. (Vertical scale greatly exaggerated. ) 


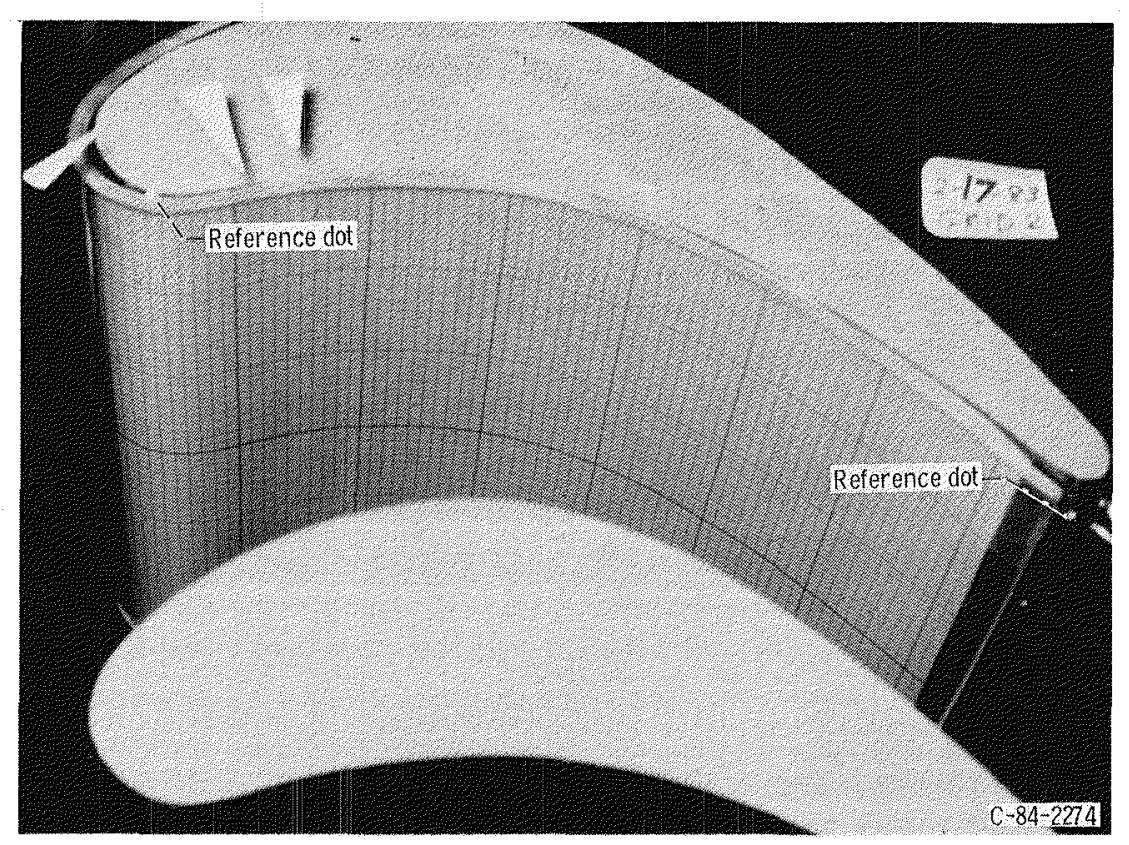

Figure 4. - Location grid, pressure side view.

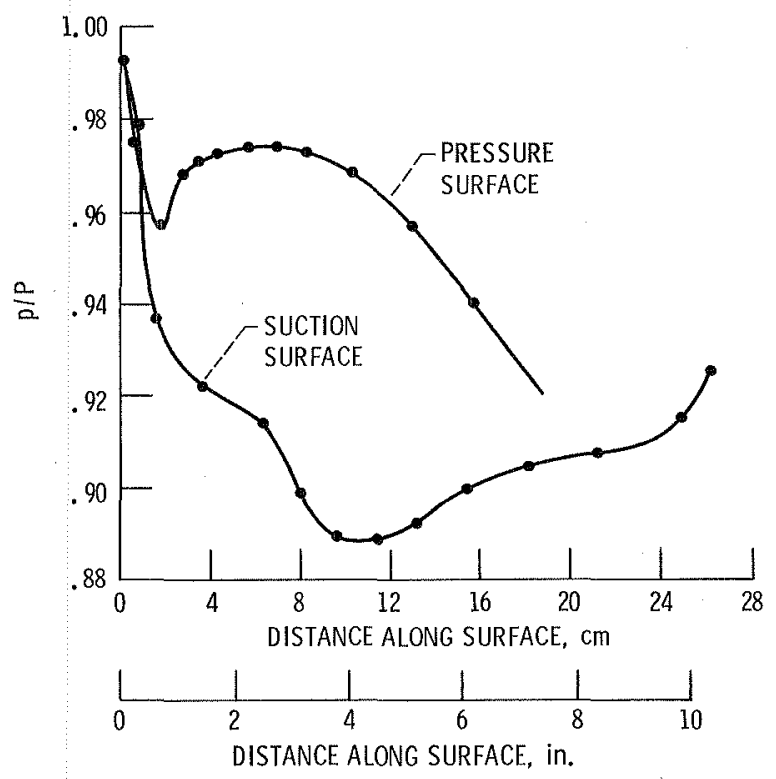

Figure 5. - Measured pressure distribution around blade. Inlet free-stream conditions: velocity, $71.3 \mathrm{~m} / \mathrm{sec}(234$ $\mathrm{ft} / \mathrm{sec})$; temperature, $29.5^{\circ} \mathrm{C}\left(85.1^{\circ} \mathrm{F}\right)$, pressure

91. $84 \mathrm{kPa}$ (13. 32 psia). 


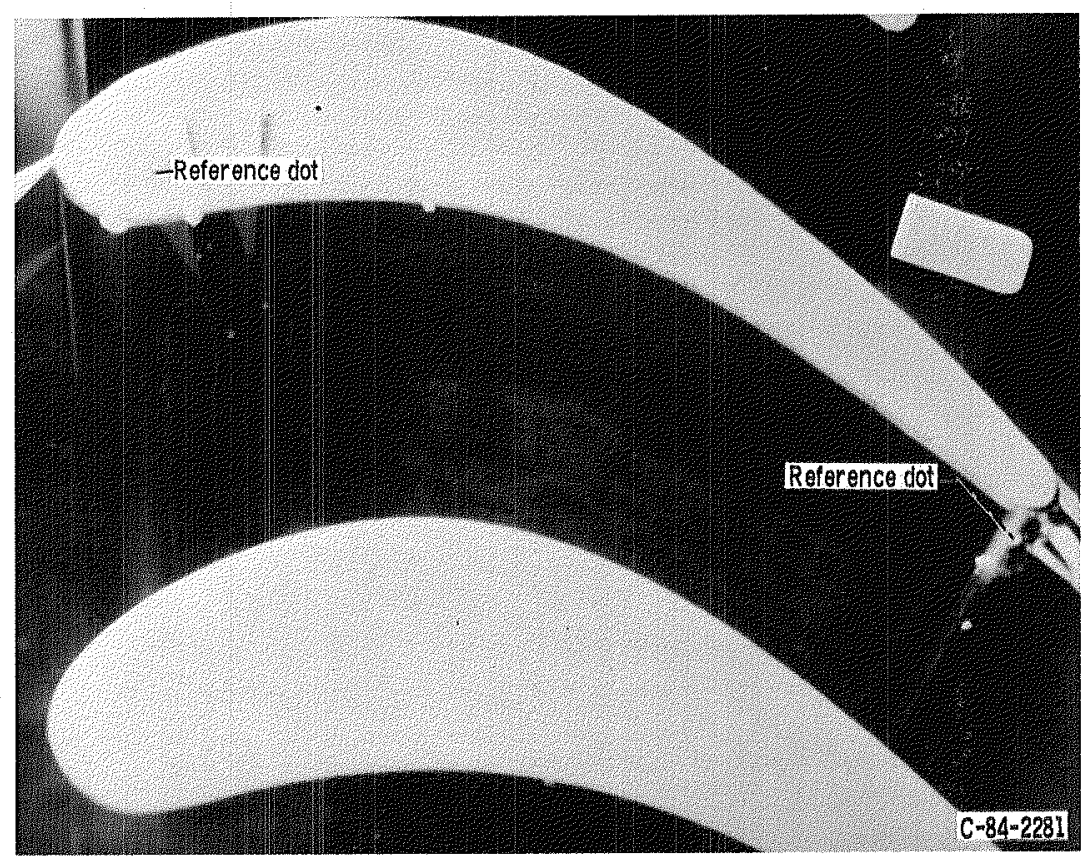

(a) Lowest heat flux value, $\mathrm{Re}=2.8 \times 10^{5}$.

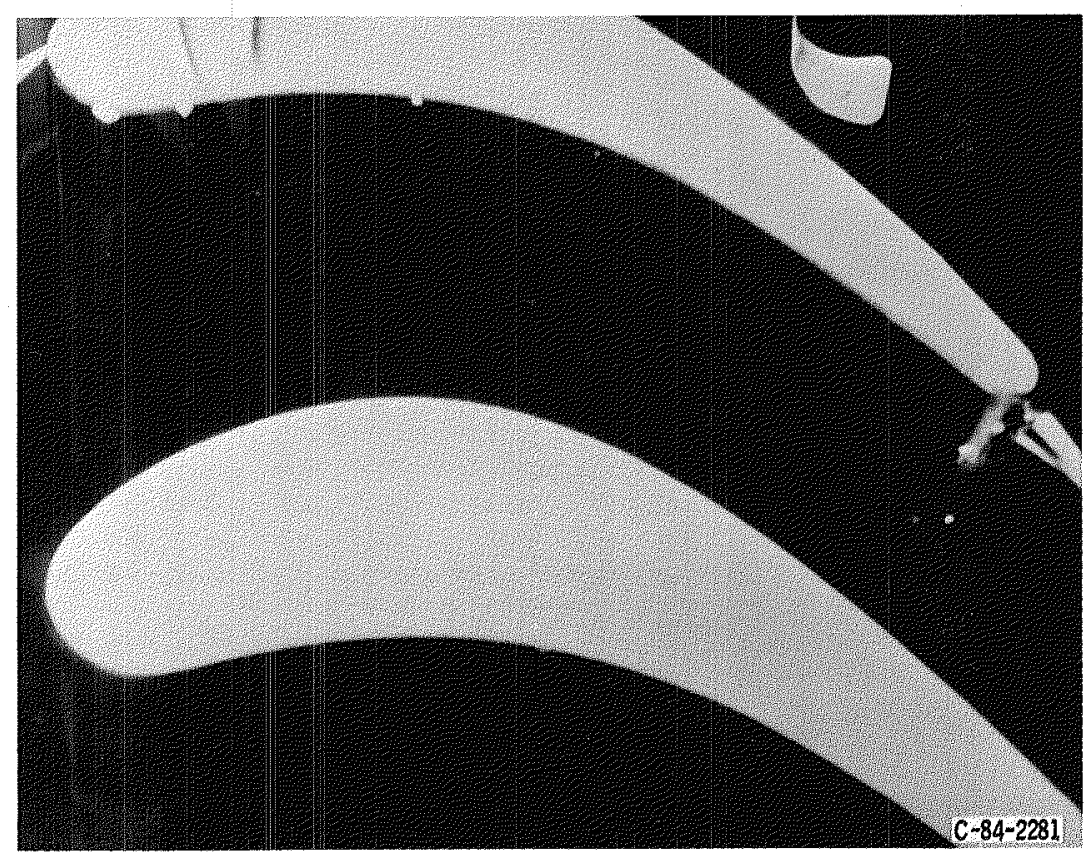

(b) Highest heat flux value, $\mathrm{Re}=7.6 \times 10^{5}$.

Figure 6. - Temperature patterns. 


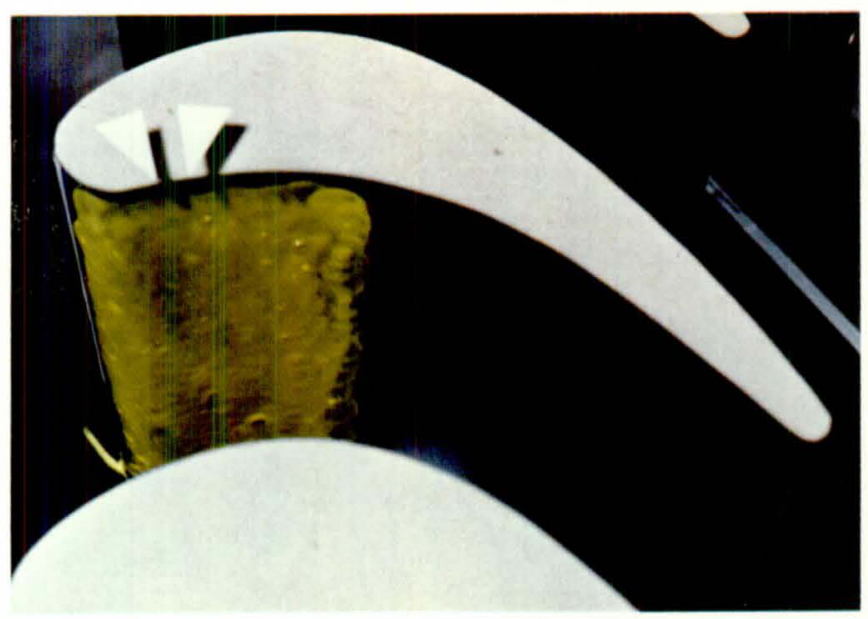

(a) Before airflow started, pressure side.

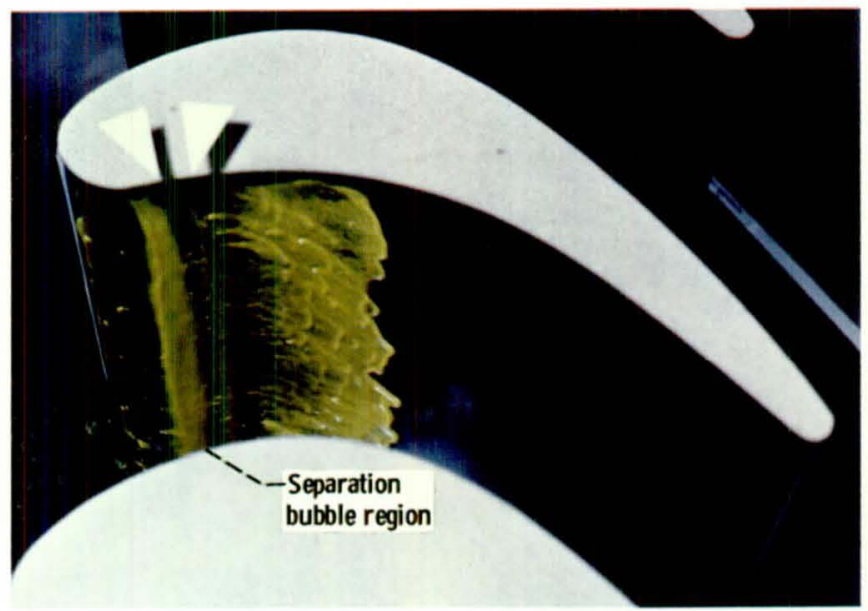

(b) After 2 minutes of airflow, pressure side.

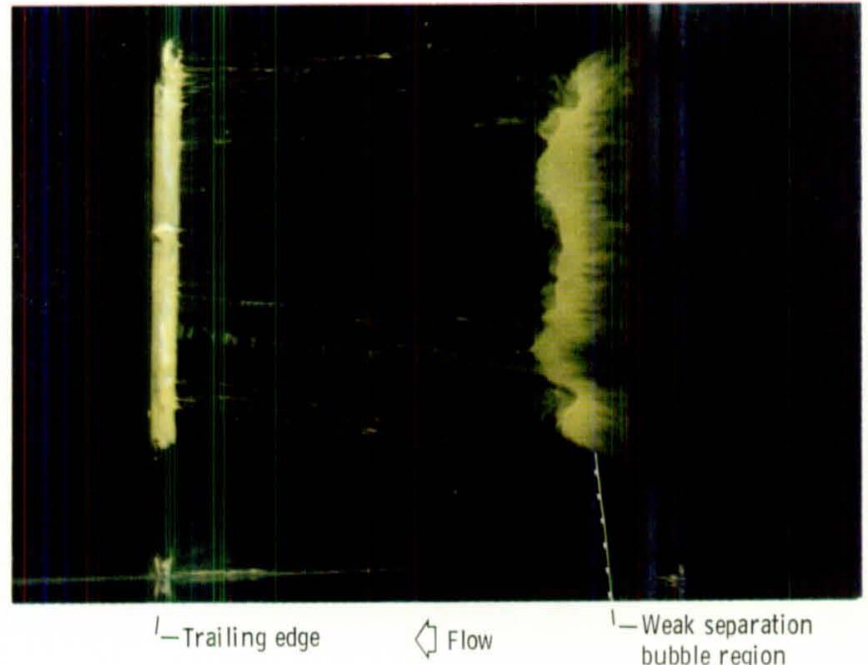

(c) After airflow, suction side.

Figure 7. - Flow visualization using yellow pigmented oil. 


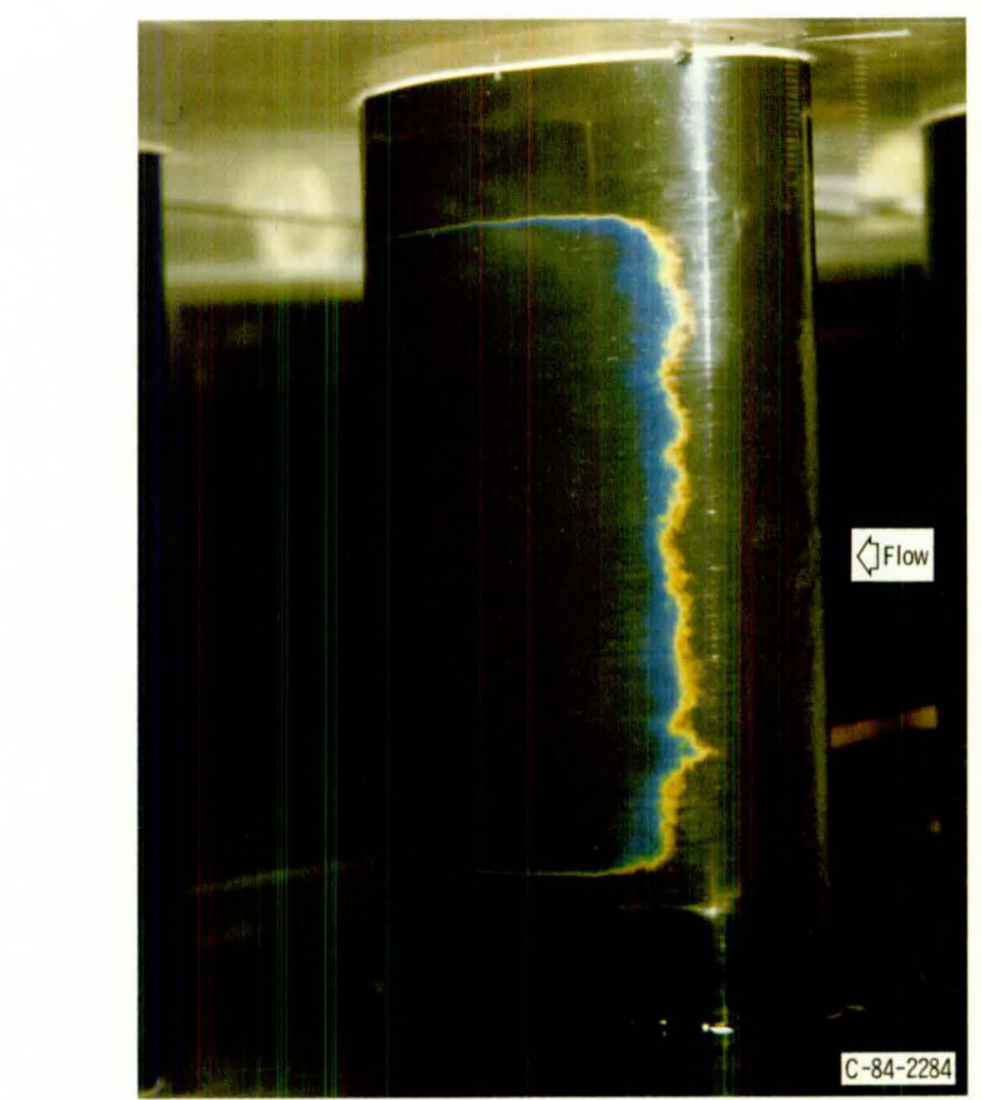

(a) Leading edge, $\operatorname{Re} \cdot 4.2 \times 10^{5}$.

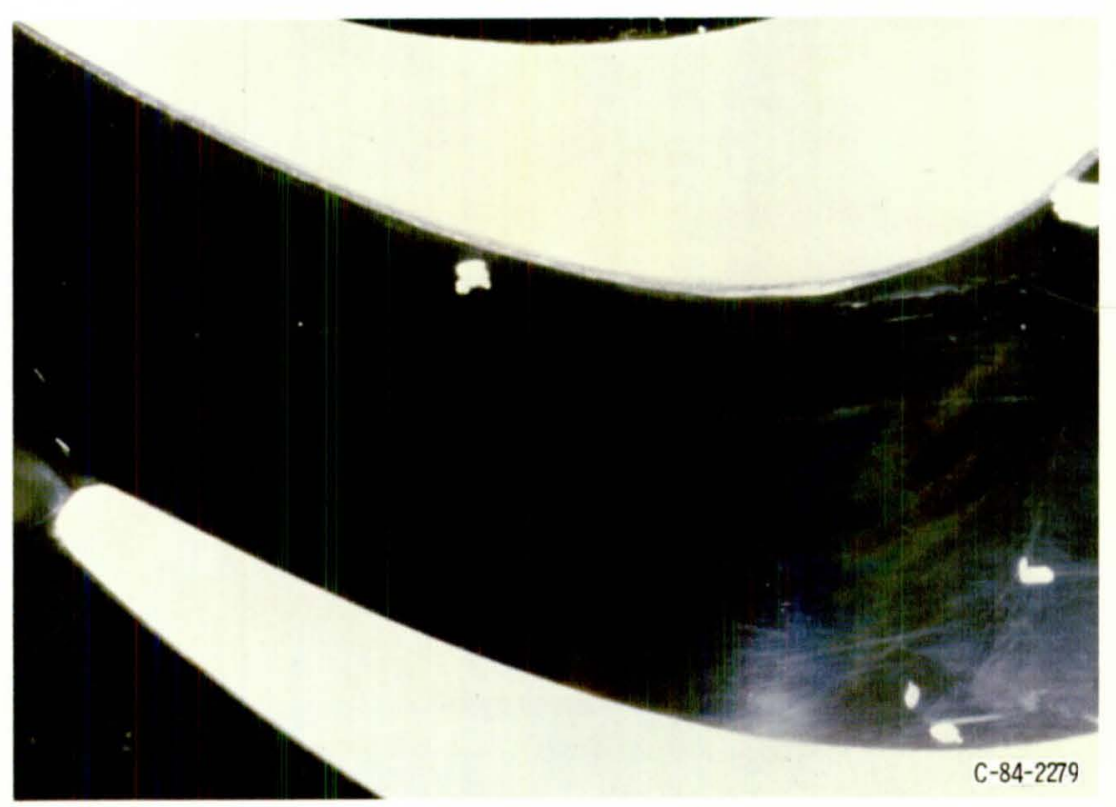

(b) Midchord, $R e=4.2 \times 10^{5}$.

Figure 8. - Suction-side temperature pattern. 


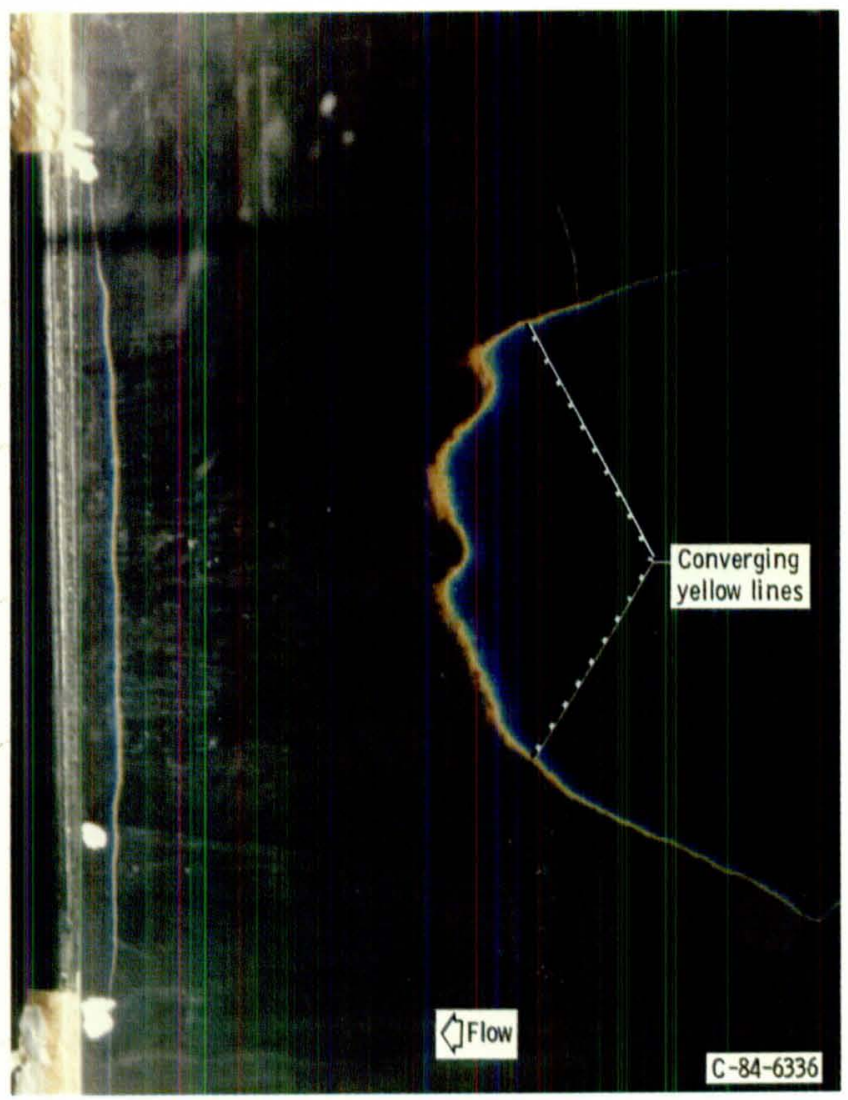

(c) Trailing edge, $\mathrm{Re}=4.2 \times 10^{5}$.

Figure 8. - Concluded.

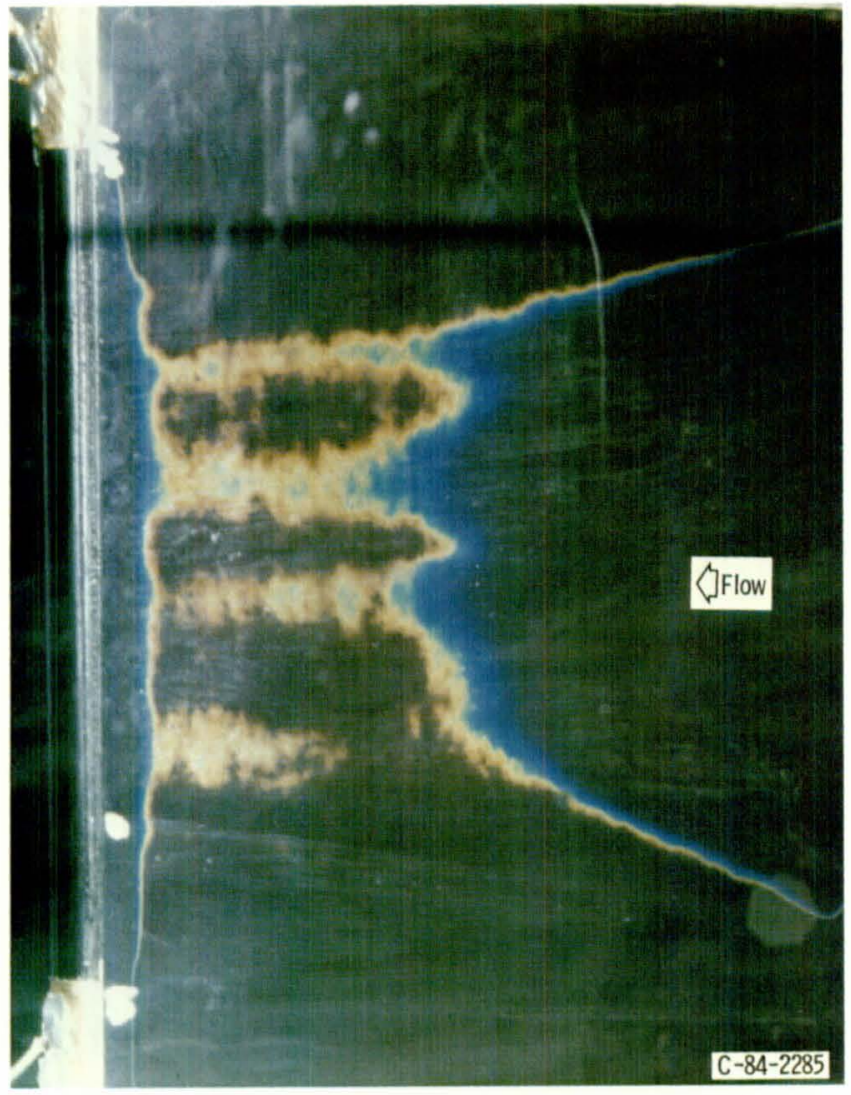

Figure 9. - Suction-side trailing-edge periodic temperature pattern, $R e=4.2 \times 10^{5}$. 


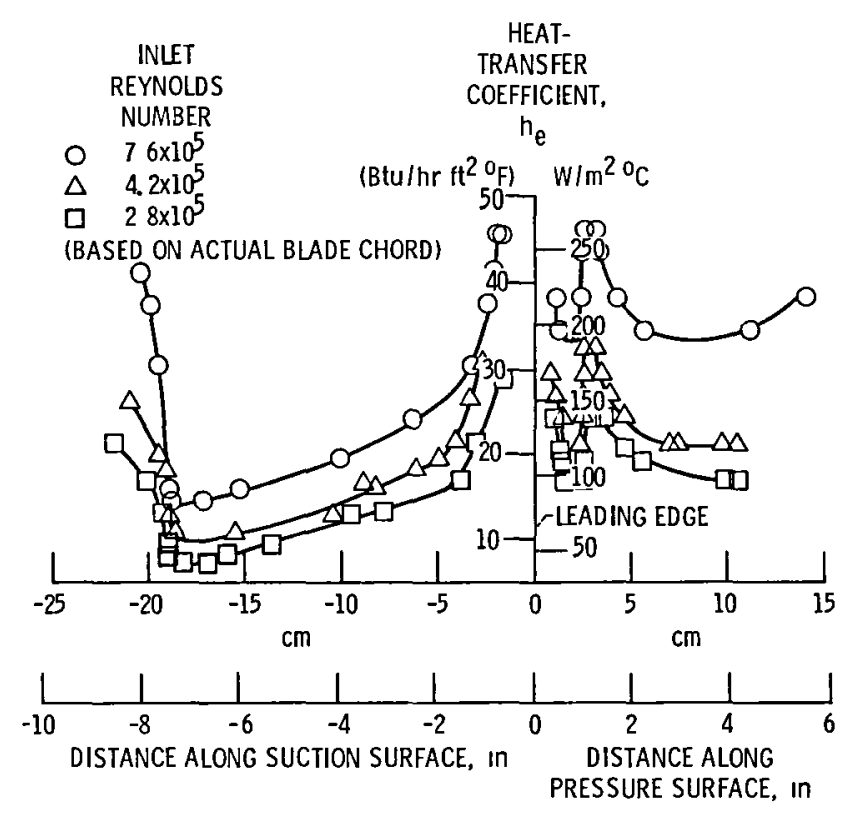

Figure 10. - Heat-transfer coefficient map.
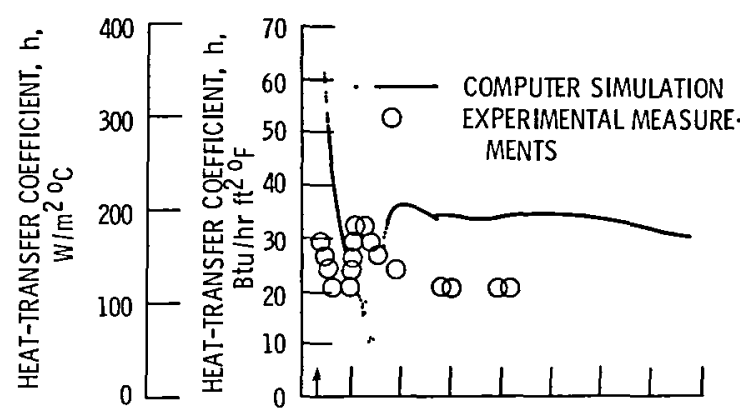

(a) Heat-transfer coefficient
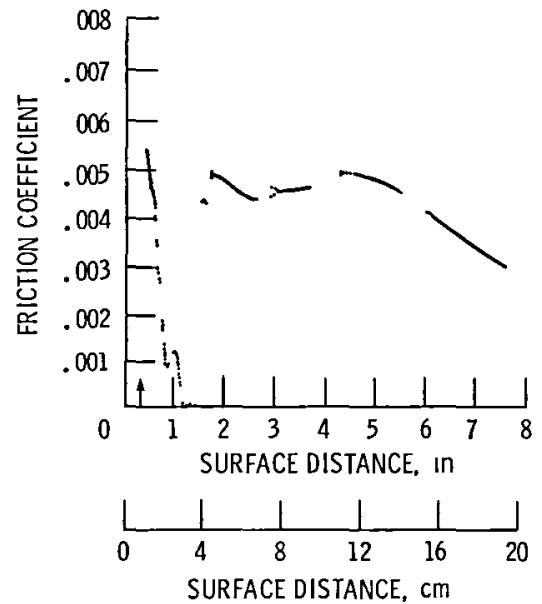

(b) Friction coefficient.

Figure 11. - Pressure-side coefficients versus blade surface distance, $\mathrm{Re}=76 \times 10^{5}$
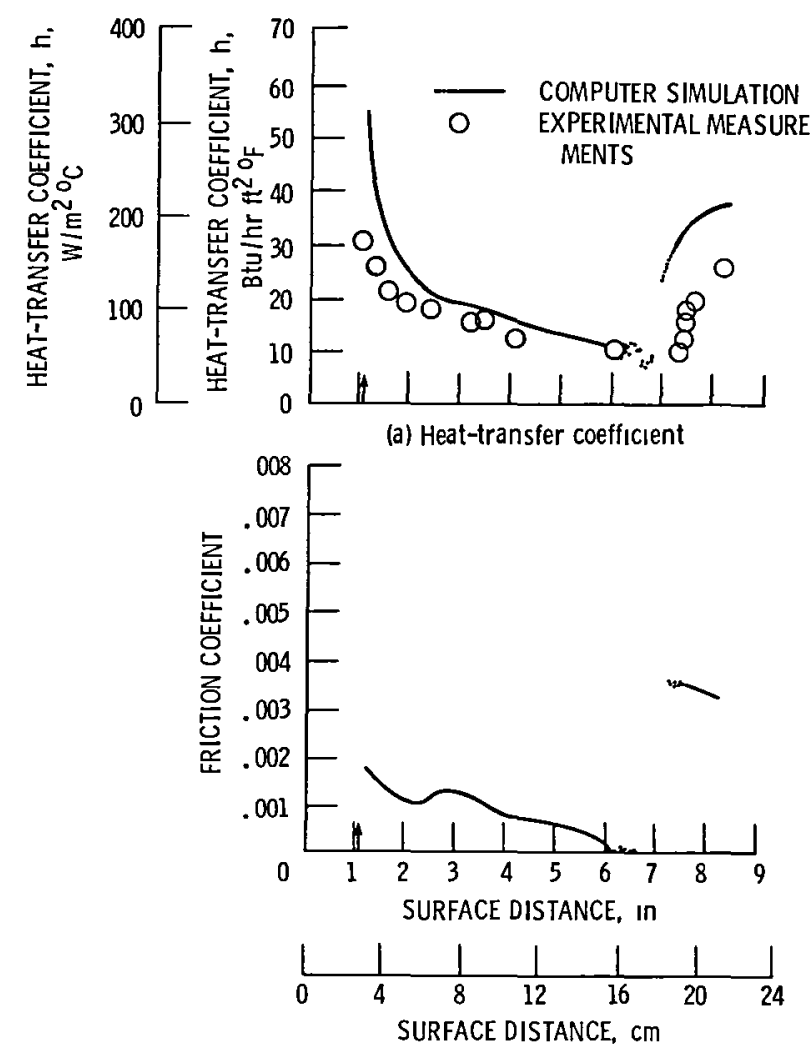

(b) Friction coefficient.

Figure 12 - Suction-side coefficients versus blade surface distance, $\operatorname{Re}=7.6 \times 10^{5}$ 


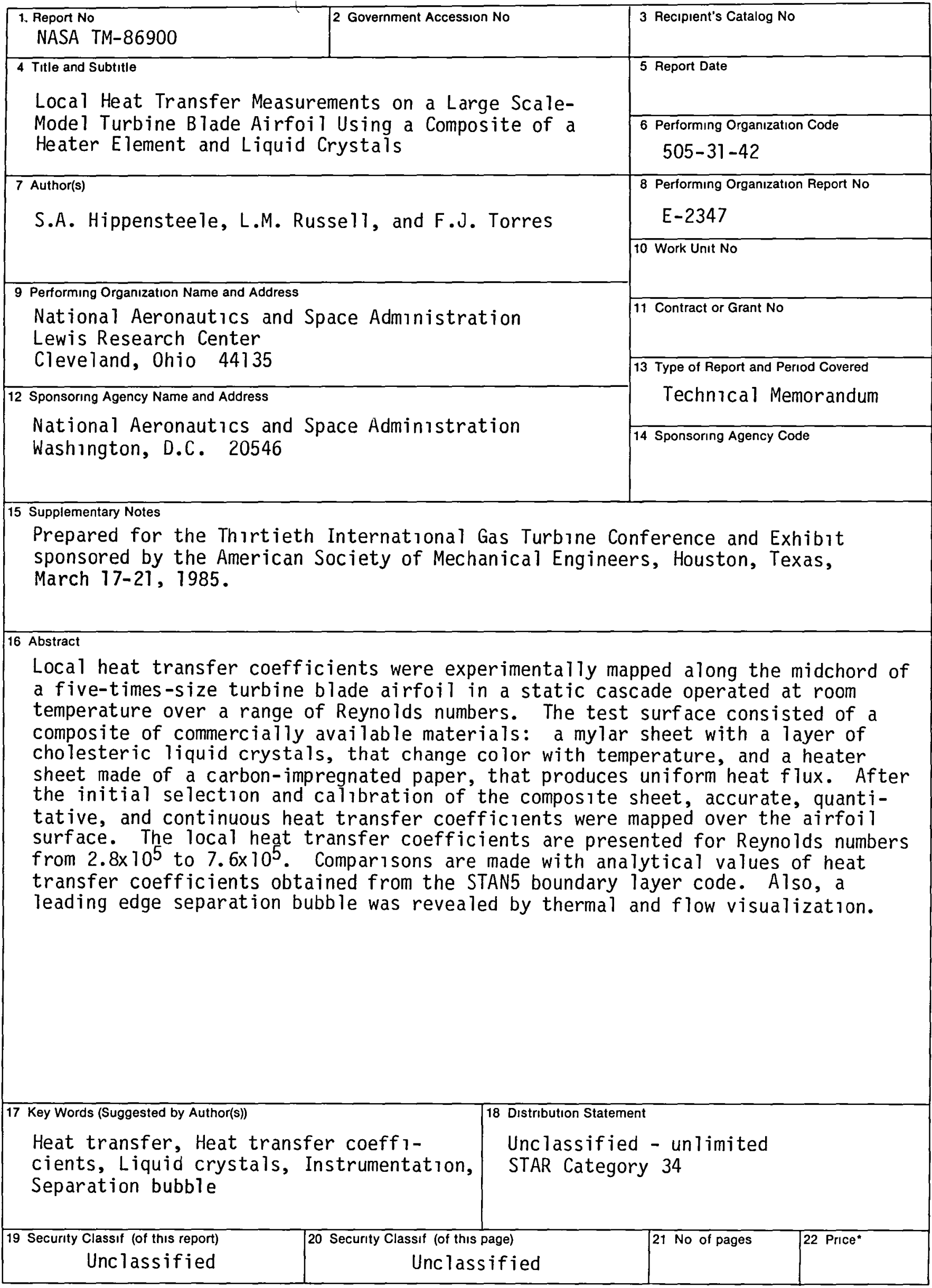

*For sale by the Natıonal Technical Information Service, Sprıngfield, Vırgınia 22161 
End of Document 